\title{
Influence of soil specimen preparation on results of its organic matter content laboratory determination
}

\author{
Giang Nguyen ${ }^{1,2}$ * \\ ${ }^{1}$ University of Žilina, Faculty of Civil Engineering, Univerzitná 8215/1, 01026 Žilina, Slovakia \\ ${ }^{2}$ University of Bielsko-Biela, Willowa 2, 43-309 Bielsko-Biala, Poland
}

\begin{abstract}
Paper deals with influence of soil specimen preparation on values of its organic matter content, determined by laboratory tests. Totally 54 specimens of soils CG, CL, CI and CH from Lipnik, Międzyrzecze and Nieboczowy, Poland were tested. To obtain values of soils organic matter content, the oxidation method introduced in the Polish Standard PN-88/B-04481 was applied. The tests were carried out for particles smaller than $2 \mathrm{~mm}$. For every sample, 3 specimens (every with a mass about $10 \mathrm{~g}$ of dry soil) were prepared by such a way that the first one is taken from whole sample after drying about $200 \mathrm{~g}$ of wet soil. The second and third one were taken from $50 \mathrm{~g}$ of remaining sample mass after taking the first one. As an oxidizing agent, the $30 \%$ hydrogen peroxide solution was used. The results show that values of organic matter content of soils range from $0.03 \%$ to $2.74 \%$. The largest difference in values of organic matter content, caused by specimen preparation, was $0.38 \%$ (absolute difference), corresponding to relative difference $15.86 \%$. The smallest difference was null. Mentioned difference causes negligible difference in soil erodibility factor $\mathrm{K}$ hence negligible difference in soil erosion rate in mentioned locations.
\end{abstract}

\section{Introduction}

Soil erosion is a serious problem and effects nature as so as various artificial slopes. There are many factors determining soil erosion such as climate, soil characteristics, topography, ground cover, duration of soil exposure and human activities. Various techniques are applied to protect a slope from erosion. One of them is application of geotextile ropes, placed meandrically on the slope [1-5]. To evaluate effectiveness of this technique, it is necessary to determine soil lost rate by erosion for parts of slope with and without ropes application.

To calculate soil lost rate by erosion, Universal Soil Loss Equation (USLE) [6] can be applied. To calculate soil lost rate by USLE, one should know values of soil erodibility factor K. There are many formulas for soil erodibility factor K calculation; some of them need only soil grain-size distribution; some of them need additionally soil organic matter

\footnotetext{
* Corresponding author: giang.nguyen@,fstav.uniza.sk
} 
content (SOM) and some of them require further data such as soil structure code used in soil classification and water permeability class as input data. To evaluate effectiveness of the technique using geotextile ropes in Lipnik, Nieboczowy and Międzyrzecze (Poland), we determine soil lost rate by erosion using the USLE and we apply SOM in calculation of soil erodibility factor $\mathrm{K}$.

In this paper we will introduce influence of soil specimen preparation on values of its SOM, determined by laboratory tests. We will also analyse impact of different values of SOM, caused by specimen preparation, on value of soil erodibility factor $\mathrm{K}$ and then also on annual soil erosion rate in above mentioned locations.

\section{Determination of SOM}

There are many methods to determine SOM but taken into account our laboratory equipment, purpose of the test (obtained value of SOM will be applied in determination of soil erodibility factor K) and geographical locations of soils (Poland), it will be suitable to carry out tests for determination of SOM in accordance with the article 4.4.4.1 of Polish Standard PN-88/B-04481[7] (determination of the organic content by the oxidation method).

By mentioned article 4.4.4.1, a specimen of mass not less than $300 \mathrm{~g}$ should be taken from the soil intended for testing, thoroughly disintegrate and mix, and then applying the quartering method to decrease specimen mass, that after drying to a constant mass at $105-110^{\circ} \mathrm{C}$, the mass of tested soil was $30-50 \mathrm{~g}$. Next step is to weigh in a beaker (mass of the beaker will be $\mathrm{m}_{\mathrm{t}}$ ) about $10 \mathrm{~g}$ of soil and weigh it all to the nearest $0.01 \mathrm{~g}$ (mass of the beaker and soil will be $\mathrm{m}_{\mathrm{st}}$ ). Then pour about $30 \mathrm{~cm}^{3}$ of $30 \%$ hydrogen peroxide solution into the beaker, cover the beaker and gradually warm up to approximately $60^{\circ} \mathrm{C}$, making sure that the content of the beaker does not foam too strong and does not spray. Heating (preferably on a water bath) should be carried out during about 3 hours to the moment when after adding another $10 \mathrm{~cm}^{3}$ of $30 \%$ hydrogen peroxide solution, there are no gas bubbles. After the heating is finished, the contents of the beaker should be boiled, after that we will obtain slurry of a dense consistency; content of the beaker should not splatter. Then the beaker is placed in a dryer and dries to constant mass at $105-110^{\circ} \mathrm{C}$. After cooling in the desiccator to room temperature, a beaker together with content should be weighed with accuracy not less than $0.01 \mathrm{~g}$ (mass of the beaker and soil after drying will be $\mathrm{m}_{\mathrm{u}}$ ). SOM is calculated applying formula:

$$
S O M=\left(m_{s t}-m_{u}\right) /\left(m_{s t}-m_{t}\right)
$$

By the article 4.4.4.1, it is not necessary to carry out more specimens and calculate their average, so practically value of organic matter content obtained from one specimen could be sufficient.

\section{SOM of soils in Lipnik, Międzyrzecze and Nieboczowy}

To determine SOM in Lipnik, Międzyrzecze and Nieboczowy, laboratory tests of soil in accordance with article 4.4.4.1 [7] were carried out. Soil samples' locations can be seen in Fig. 1 up to Fig. 4.

Soil samples from Lipnik were taken before application of anti-erosion measures so there are only 4 samples, in the following marked as L1, L2, L3 and L4, from which sample L4 was taken from the soil, later applied as cover soil ( $\mathrm{L}$ is the first letter of Lipnik). Soil samples from Międzyrzecze and Nieboczowy were taken after application of anti-erosion measures so there can be difference between cover soil (covering the ropes) and subsoil 


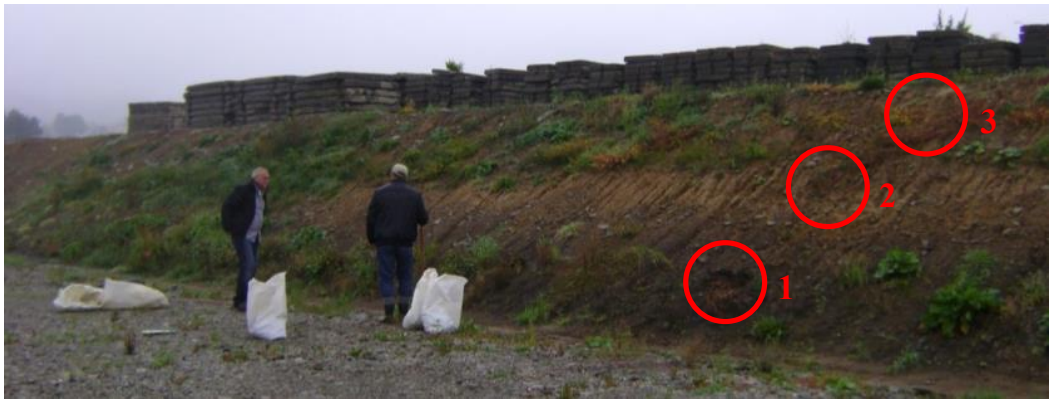

Fig. 1. Soil sample No. 1, 2 and 3 locations in Lipnik.

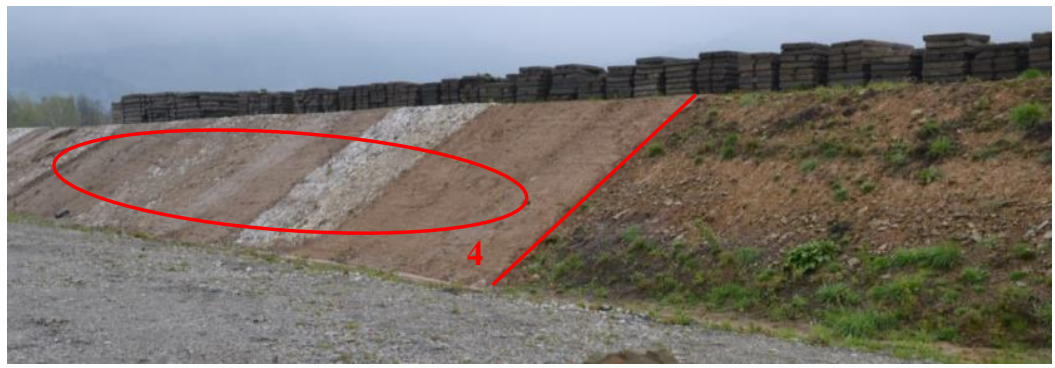

Fig. 2. Soil sample No. 4 location in Lipnik (photo Prof. Broda).

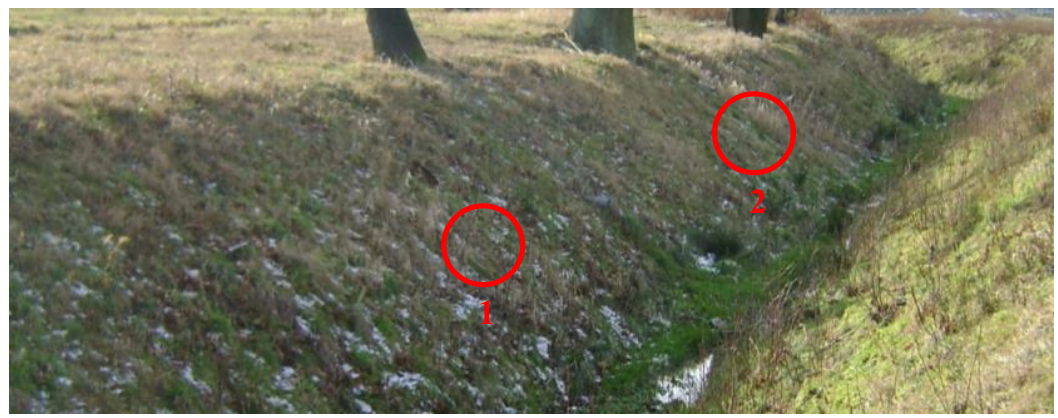

Fig. 3. Soil sample No. 1 and 2 locations in Międzyrzecze.

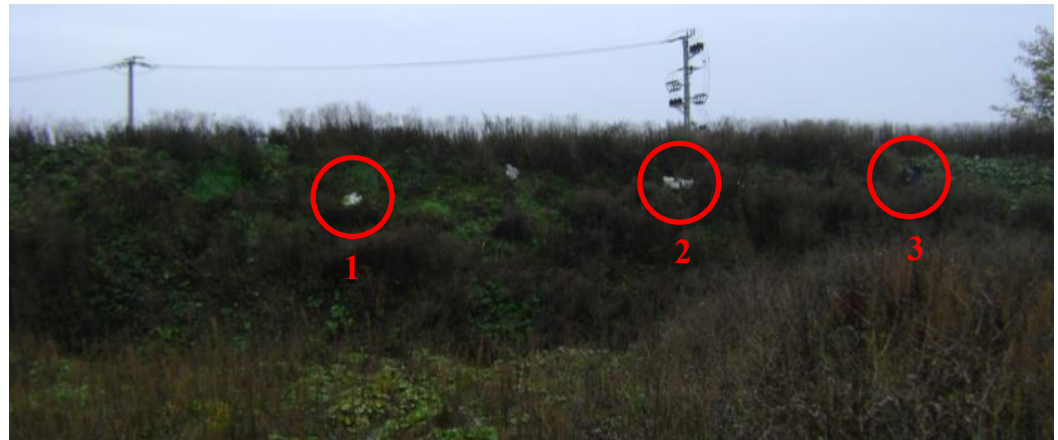

Fig. 4. Soil sample No. 1, 2 and 3 locations in Nieboczowy. 
(under the ropes). From mentioned reason 2 soil samples (cover soil and subsoil) from every sample location were taken and analysed. Samples are marked based on location (No. 1, 2 or 3) and a letter (letter "a" for upper layer and letter "b" for lower layer), so e. g. specimen marked as "M1a" is taken from Międzyrzecze, location No. 1 and it is cover soil; specimen marked as "N3b" is taken from Nieboczowy, location No. 3 and it is subsoil. So total number of soil samples is 14 .

Determination of soil particles size distribution was carried out in accordance with the BS 1377:1990. Part 2 (wet sieving method and sedimentation by the hydrometer method) [8]. Soil basic parameters such as water content $(\mathrm{w})$, liquid limits $\left(\mathrm{w}_{\mathrm{L}}\right)$ and plastic limits $\left(\mathrm{w}_{\mathrm{P}}\right)$ were also determined in accordance with mentioned standard. Based on obtained values, soils classifications were carried out in accordance with the British Standard BS 5930:2015 [9]. Soils classifications are posted in Tab. 1.

By the note in article 3.4.2.5 of the BS 1377 : 1990. Part 3 [10], it is assumed that any material retained on the $2 \mathrm{~mm}$ test sieve will not contain organic matter. If this is seen not to be true, the pieces of organic matter should be removed by hand, crushed to pass a $2 \mathrm{~mm}$ test sieve and incorporated in the fraction passing the sieve.

In our case, representative part of a sample of mass about $800 \mathrm{~g}$ was chosen, from which a sample of about $200 \mathrm{~g}$ was obtained by the quartering method. The sample was then disintegrated by hand and sieved over $2 \mathrm{~mm}$ sieve. Particles passed the sieve $2 \mathrm{~mm}$ were dried, from which the specimen No. 1 was taken and the "TestNo1" for this specimen was carried out. By this way, the first 14 specimens were taken, marked with laboratory number L1-1, L2-1, M1a-1, N3b-1 etc.. After that about 50g from remaining part was taken. In Fig. 5 we can see $50.014 \mathrm{~g}$ of the sample L1.

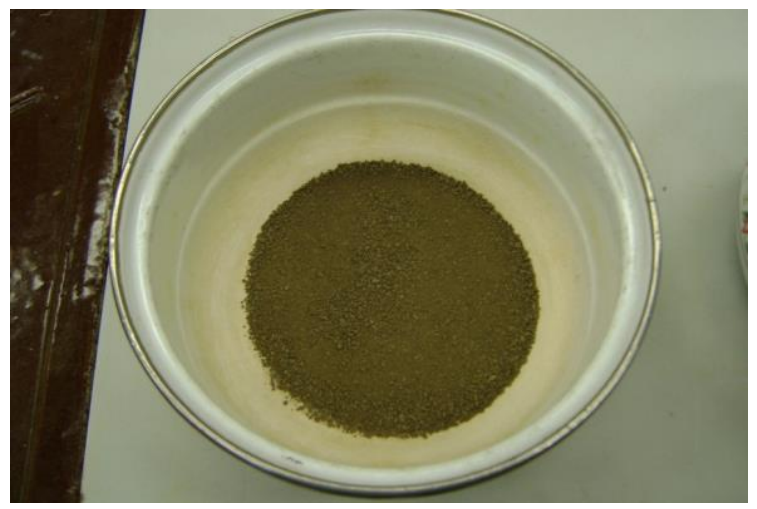

Fig. 5. Amount 50.014g of the sample L1 from Lipnik.

In the next step, sample of mass $50.014 \mathrm{~g}$ was divided to 4 parts by quartering method and 2 specimens were taken from opposite parts (every specimen has mass about 10g). For the first one, "TestNo2" was carried out and for the second one, "TestNo3" was carried out. These 2 specimens from the sample L1 were marked as L1-2 and L1-3, which can be seen in beakers No. 1a and 1b in Fig. 6. So for every sample, 3 tests were carried out: "TestNo1" for the specimen taken from whole sample; "TestNo2" and "TestNo3" for the specimens taken from about $50 \mathrm{~g}$ of sample remaining part after taking the first specimen. Totally $14 \times 3=54$ tests were carried out.

Since we have only $35 \%$ hydrogen peroxide, $300 \mathrm{ml}$ of $30 \%$ hydrogen peroxide solution (for 10 specimens in 10 beakers, which were tested at the same time) was prepared by adding $257 \mathrm{ml}$ of $35 \%$ hydrogen peroxide to $43 \mathrm{ml}$ of distilled water. After pouring $30 \mathrm{~cm}^{3}$ of $30 \%$ hydrogen peroxide solution into the beaker, one can see boiling mix of soil and 
hydrogen peroxide solution (see state of specimens L1-2 and L1-3 in breakers No. 1a and 2a 12 minutes after pouring hydrogen peroxide in Fig. 7). After 30 minutes from pouring hydrogen peroxide, breakers with mix of soil and hydrogen peroxide solution were placed in a dryer with temperature set to $60^{\circ} \mathrm{C}$ and drying during 3 hours. After 3 hours another 10 $\mathrm{cm}^{3}$ of $30 \%$ hydrogen peroxide solution wad added. It was found that practically no gas bubbles were seen in breakers. Breakers with mix of soil and hydrogen peroxide solution were placed again in a dryer with temperature set to $60^{\circ} \mathrm{C}$ and after 1 hour, temperature was set to $105^{\circ} \mathrm{C}$ and specimens were dried further 16 hours. SOM is calculated applying formula (1) and results are introduced in Tab. 1.

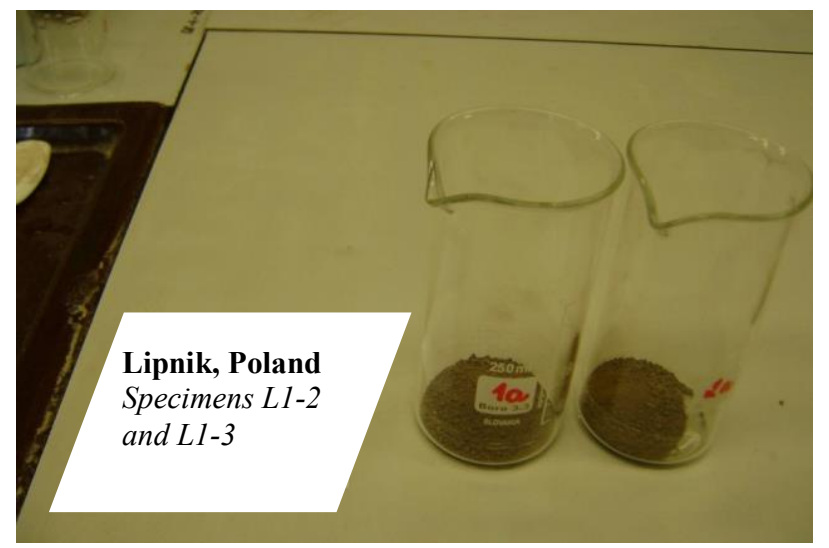

Fig. 6. Specimen L1-2 (left, mass of 10.285g) and L1-3 (right, mass of 10.506g) from Lipnik.

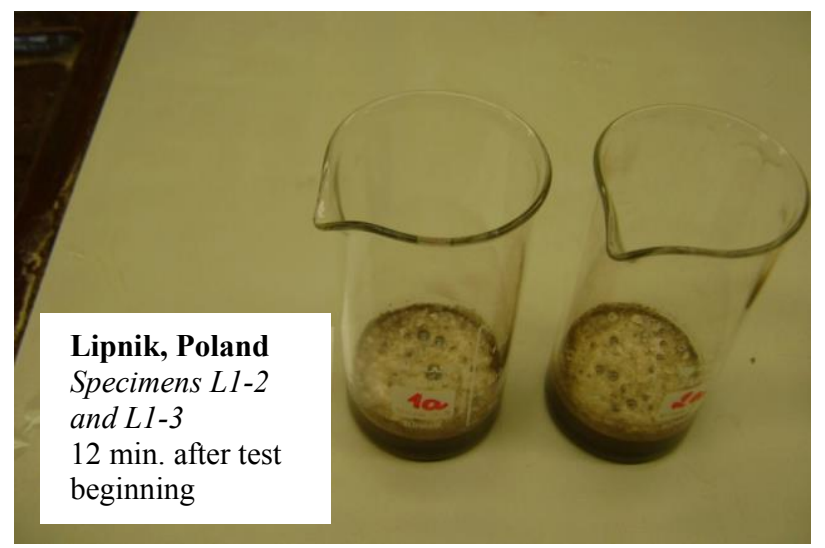

Fig. 7. State of specimens L1-2 (left) and L1-3 (right) in breakers No. 1a and 2a

(12 minutes after pouring hydrogen peroxide).

As it was mentioned in the author's report [11], analysis of influence of values of SOM on soil erodibility factor K can be carry out after obtaining values of SOM. In this case, soil erodibility factor $\mathrm{K}$ will be calculated applying formula in [6]:

$$
100 K=2.1 * M^{1.14} * 10^{-4} *(12-a)+3.25 *(b-2)+2.5 *(c-3)
$$

where: 
M: particle-size parameter which equals percentage of fraction $0.002-0.1 \mathrm{~mm}$ times the quantity 100 minus clay percentage,

a: $\operatorname{SOM}(\%)$, if SOM is larger than $4 \%$, then $a=4$,

$\mathrm{b}$ : soil structure code used in soil classification (very fine granular: 1, fine granular: 2 , medium or coarse granular: 3 and very coarse granular: 4),

c: water permeability class (rapid: $1\left(\mathrm{k}_{\mathrm{f}} \geq 3.10^{-5} \mathrm{~m} / \mathrm{s}\right)$; moderate to rapid: $2\left(3.10^{-5} \mathrm{~m} / \mathrm{s} \geq \mathrm{k}_{\mathrm{f}}\right.$ $\left.\geq 1.5 .10^{-5} \mathrm{~m} / \mathrm{s}\right)$; moderate: $3\left(1.5 .10^{-5} \mathrm{~m} / \mathrm{s} \geq \mathrm{k}_{\mathrm{f}} \geq 4.8 .10^{-6} \mathrm{~m} / \mathrm{s}\right)$; slow to moderate: $4\left(4.8 .10^{-}\right.$ $\left.{ }^{6} \mathrm{~m} / \mathrm{s} \geq \mathrm{k}_{\mathrm{f}} \geq 1.2 \cdot 10^{-6} \mathrm{~m} / \mathrm{s}\right)$; slow: $5\left(1.2 .10^{-6} \mathrm{~m} / \mathrm{s} \geq \mathrm{k}_{\mathrm{f}} \geq 3.10^{-7} \mathrm{~m} / \mathrm{s}\right)$ and very slow: $6\left(3.10^{-7} \mathrm{~m} / \mathrm{s} \geq \mathrm{k}_{\mathrm{f}}\right.$ $\geq)$ ), see [12] .

Obtained values of $\mathrm{K}$ should be multiply by 1.313 to obtain $\mathrm{K}$ in unit (t.ha.h)/(ha.MJ.cm). Values of soil erodibility factor K are introduced in Tab. 2 (see the author's report [11] for further input data needed for calculation of soil erodibility factor $\mathrm{K}$ which are not posted here from the reason of restricted 8 pages of the paper).

Table 1. Values of SOM and their comparison.

\begin{tabular}{|c|c|c|c|c|c|c|c|c|c|c|c|c|c|c|}
\hline \multirow{3}{*}{$\begin{array}{c}\text { Locations } \\
\text { Sample number }\end{array}$} & \multicolumn{14}{|c|}{$\operatorname{SOM}(\%)$} \\
\hline & \multicolumn{4}{|c|}{ Lipnik } & \multicolumn{4}{|c|}{ Międzyrzecze } & \multicolumn{6}{|c|}{ Nieboczowy } \\
\hline & L1 & L2 & $\mathbf{L 3}$ & L4 & M1a & M1b & M2a & M2b & N1a & N1b & $\mathrm{N} 2 \mathrm{a}$ & $\mathbf{N} 2 b$ & N3a & $\mathbf{N} 3 \mathrm{~b}$ \\
\hline Classification (1) & $\mathrm{CG}$ & $\mathrm{CL}$ & $\mathrm{CI}$ & CI & $\mathrm{CL}$ & $\mathrm{CI}$ & $\mathrm{CL}$ & $\mathrm{CI}$ & $\mathrm{CH}$ & $\mathrm{CH}$ & $\mathrm{CH}$ & $\mathrm{CH}$ & $\mathrm{CH}$ & $\mathrm{CI}$ \\
\hline Soil type & NA & NA & NA & NA & Cover & Subsoil & Cover & Subsoil & Cover & Subsoil & Cover & Subsoil & Cover & Subsoil \\
\hline TestNo1 & 2.74 & 0.97 & 2.00 & 1.37 & 1.00 & 0.22 & 1.02 & 0.07 & 2.56 & 0.38 & 1.01 & 0.84 & 1.36 & 0.62 \\
\hline TestNo2 & 2.21 & 1.11 & 1.93 & 1.30 & 1.01 & 0.18 & 1.12 & 0.13 & 2.52 & 0.42 & 1.01 & 0.90 & 1.35 & 0.47 \\
\hline TestNo3 & 2.52 & 1.05 & 1.81 & 1.07 & 0.91 & 0.06 & 1.10 & 0.03 & 2.47 & 0.28 & 1.17 & 0.85 & 1.43 & 0.47 \\
\hline $\begin{array}{l}\text { Average [(4) and } \\
\text { (5)] }\end{array}$ & 2.37 & 1.08 & 1.87 & 1.19 & 0.96 & 0.12 & 1.11 & 0.08 & 2.50 & 0.35 & 1.09 & 0.88 & 1.39 & 0.47 \\
\hline $\begin{array}{l}\text { Abs. diff. [(4) and } \\
(5)]\end{array}$ & $\underline{0.31}$ & 0.06 & 0.12 & 0.23 & 0.10 & 0.12 & 0.02 & 0.10 & 0.05 & 0.14 & 0.16 & 0.05 & 0.08 & $\underline{0.00}$ \\
\hline $\begin{array}{l}\text { Relative diff. ([(4) } \\
\text { and (5)], [\%] (8) }\end{array}$ & 14.03 & 5.71 & 6.63 & 21.50 & 10.99 & 200.0 & 1.82 & $\underline{333.3}$ & 2.02 & 50.00 & 15.84 & 5.88 & 5.93 & $\underline{0.00}$ \\
\hline $\begin{array}{l}\text { Abs. diff. [(3) and } \\
(6)]\end{array}$ & $\underline{0.38}$ & 0.11 & 0.13 & 0.19 & 0.04 & 0.10 & 0.09 & $\underline{0.01}$ & 0.06 & 0.03 & 0.08 & 0.04 & 0.03 & 0.15 \\
\hline $\begin{array}{l}\text { Relative diff. ([(3) } \\
\text { and (6)], [\%] (10) }\end{array}$ & 15.86 & 11.34 & 6.95 & 15.61 & 4.17 & $\underline{83.33}$ & 8.82 & 14.29 & 2.61 & 8.57 & 7.92 & 4.00 & $\underline{2.21}$ & 31.91 \\
\hline $\begin{array}{l}\text { Average }[(3),(4) \\
\text { and (5)] }\end{array}$ & 2.49 & 1.04 & 1.91 & 1.25 & 0.97 & 0.15 & 1.08 & 0.08 & 2.52 & 0.36 & 1.06 & 0.86 & 1.38 & 0.52 \\
\hline
\end{tabular}

As we can see from the Tab. 1, values of SOM of tested soils range from $0.03 \%$ (Międzyrzecze, Mb2, TestNo3, line (5)) to 2.74\% (Lipnik, L1, TestNo1, line (3)). Values of SOM of cover soils are much larger than values of SOM of subsoils in all cases (see Międzyrzecze M1a, M2a and Nieboczowy N1a, N2a and N3a). It could be caused by proposed higher values of SOM of cover soils at the beginning but we can also propose that values of SOM of cover soils are increasing by time.

There are also differences between values of SOM obtained from TestNo1 and TestNo2 (even specimens, every with mass of about $10 \mathrm{~g}$, were taken from the same sample of mass about $50 \mathrm{~g}$ ). The largest difference is $0.31 \%$ (in absolute value, in this case, $\%$ is a unit of SOM) equal to relative difference $14.03 \%$ (see Lipnik L1, lines (7) and (8)). The smallest difference is practically null (see Nieboczowy N3b, lines (7) and (8)). The largest relative difference is up to $333.3 \%$ (see Międzyrzecze M2b, line (8)) which is caused by the fact that there are very small values of SOM so small absolute difference gives large relative difference. 
Table 2. Values of soil erodibility factor $\mathrm{K}$

\begin{tabular}{|c|c|c|c|c|c|c|c|c|c|}
\hline & & & & $\mathrm{K}(\mathrm{t} * \mathrm{~h}$ & a*h $) /($ ha* $N$ & $\left.4 J^{*} \mathrm{~cm}\right)$ & & & \\
\hline Locations & & Lip & nik & & Międz & yrzecze & & Nieboczow & \\
\hline Sample number & L1 & L2 & $\mathbf{L 3}$ & L4 & M1a & M2a & N1a & N2a & N3a \\
\hline Classification & CG & $\mathrm{CL}$ & CI & CI & $\mathrm{CL}$ & $\mathrm{CL}$ & $\mathrm{CH}$ & $\mathrm{CH}$ & $\mathrm{CH}$ \\
\hline Soil type & NA & NA & NA & NA & Cover & Cover & Cover & Cover & Cover \\
\hline TestNo1 & 2.74 & 0.97 & 2.00 & 1.37 & 1.00 & 1.02 & 2.56 & 1.01 & 1.36 \\
\hline TestNo2 & 2.21 & 1.11 & 1.93 & 1.30 & 1.01 & 1.12 & 2.52 & 1.01 & 1.35 \\
\hline TestNo3 & 2.52 & 1.05 & 1.81 & 1.07 & 0.91 & 1.10 & 2.47 & 1.17 & 1.43 \\
\hline $\begin{array}{l}\text { Average [(3), (4) and } \\
(5)]\end{array}$ & 2.49 & 1.04 & 1.91 & 1.25 & 0.97 & 1.08 & 2.52 & 1.06 & 1.38 \\
\hline $\mathrm{K}$ from TestNol & 0.0656579 & 0.0558172 & 0.0558155 & 0.0558156 & 0.0558213 & 0.0558216 & 0.0558133 & 0.0558139 & 0.0558131 \\
\hline K from TestNo2 & 0.0656584 & 0.0558171 & 0.0558156 & 0.0558157 & 0.0558213 & 0.0558215 & 0.0558134 & 0.0558139 & 0.0558131 \\
\hline $\mathrm{K}$ from TestNo3 & 0.0656581 & 0.0558171 & 0.0558158 & 0.0558160 & 0.0558215 & 0.0558215 & 0.0558134 & 0.0558138 & 0.0558130 \\
\hline $\begin{array}{l}\mathrm{K} \text { from average }[(3), \\
(4) \text { and }(5)]\end{array}$ & 0.0656582 & 0.0558171 & 0.0558156 & 0.0558157 & 0.0558214 & 0.0558215 & 0.0558134 & 0.0558139 & 0.0558131 \\
\hline
\end{tabular}

Comparing values of SOM obtained from TestNo1 (the first specimen with soil taken from whole specimen mass) and average values of SOM from TestNo2 and TestNo3 (specimens were taken from about $50 \mathrm{~g}$ of remaining part after taking the first specimen), we can see that the largest difference is $0.38 \%$ equal to relative difference $15.86 \%$ (see Lipnik L1, lines (9) and (10)). The smallest difference is $0.01 \%$ in absolute value, equal to $14.29 \%$ (see Międzyrzecze M2b, lines (9) and (10)). The largest relative difference is $83.3 \%$ (see Międzyrzecze M1b, line (10)) which is caused again by the fact that there are very small values of SOM so small absolute difference gives large relative difference.

Based on data in the Tab. 2, we can state that differences in SOM do not cause large differences in values of soil erodibility factor K (see lines (7), (8), (9) and (10) in Tab. 2) which are practically equal. Such very small differences in values of soil erodibility factor $\mathrm{K}$ give very small differences in values of mean annual actual soil erosion rate $\mathrm{E}_{\mathrm{A}}$ and mean annual potential soil erosion rate $E_{P}$ (see author's report 10/1/2018 [13] for more information on $\mathrm{E}_{\mathrm{A}}$ and $\mathrm{E}_{\mathrm{P}}$ ).

So e. g. the largest difference in SOM caused by specimen preparation $0.38 \%$ (see Tab. 1, Lipnik L1, line (9)) causes a difference in soil erodibility factor K 0.00000032 (t.ha.h)/(ha.MJ.cm) (it is a difference between K values in the Tab. 2, Lipnik L1, lines (10) and (7): $0.06565827-0.06565795=0.00000032$; the last numbers " 7 " and " 5 " are missing in the lines from the reason of readability of the Tab. 2). Such small difference causes a difference $69 \mathrm{~g} \mathrm{ha}^{-1} \mathrm{y}^{-1}$ in $\mathrm{E}_{\mathrm{A}}$ (it is $0.00048 \%$ of $14.168343 \mathrm{t} \mathrm{ha}^{-1} \mathrm{y}^{-1}$ ) and $312 \mathrm{~g} \mathrm{ha}^{-1} \mathrm{y}^{-1}$ in $\mathrm{E}_{\mathrm{P}}$ (it is $0.00048 \%$ of $64.401562 \mathrm{t} \mathrm{ha}^{-1} \mathrm{y}^{-1}$ ) which are practically as calculated only, without any impact. It means that in case of soils from Lipnik, Międzyrzecze and Nieboczowy, differences in SOM caused by specimen preparation have no influence on erosion evaluation.

However, it is necessary to note, that values of soil erodibility factor K depend not only on values of SOM but also on many other parameters (see equation (2)) so sensitivity of soil erodibility factor $\mathrm{K}$ on values of SOM can be different for various soil types. Therefore it is not possible to draw general conclusion but it requires evaluating $\mathrm{K}$ from case to case. 


\section{Conclusions}

Determination of SOM by the oxidation method by the Polish Standard PN-88/B-04481 gives reasonable values of SOM of soils from Lipnik, Międzyrzecze and Nieboczowy.

Even specimen preparation causes relatively large differences in values of SOM, such differences in case of Lipnik, Międzyrzecze and Nieboczowy have no practical impact on evaluation of erosion.

We propose that determination of SOM by the method posted here can be applied also for further locations so soil erosion rate can be evaluated and effectiveness of geotextile ropes application as anti-erosion measure can be confirmed.

The author gratefully acknowledges the funding by ERANET-CORNET consortium under the international research project PROGEO 2 "Geotextiles from Sustainable Raw Materials and Textile Waste, New Mobile Production Technology and New Application Fields in Drainage and Hydraulic Engineering" DZP/CORNET/1/20/2017.

\section{References}

1. J. Broda, A. Gawłowski, M. Rom, R. Laszczak, A. Mitka, S. Przybyło, J. GrzybowskaPietras, Tekstilec 592 (2016)

2. J. Broda, S. Przybyło, K. Kobiela-Mendrek, M, Rom, , J. Grzybowska-Pietras, R. Laszczak, Int. Biodeterior. Biodegradation 115 31-38 (2016)

3. J. Broda, A. Gawłowski, R. Laszczak, A. Mitka, S. Przybyło, J. Grzybowska-Pietras, M. Rom, Geotext Geomembranes, 451 (2017) http://dx.doi.org/10.1016/j.geotexmem.2016.07.003

4. J. Broda, J. Grzybowska-Pietras, G. Nguyen, A. Gawłowski, R. Laszczak, S. Przybyło, IOP Conf. Ser.: Mater. Sci. Eng. 254192005 (2017)

5. J. Broda, A. Gawłowski, J. Grzybowska-Pietras, M. Rom, S. Przybyło, R. Laszczak, Inżynieria Ekologiczna = Ecological Engineering 181 (2017)

6. W. H. Wischmeier, D.D. Smith, Predicting Rainfall Erosion Losses - A Guide to Conservation Planning. USDA Handbook 537 (USDA, Washington. D. C., 1978)

7. PN-88/B-04481: Building soils - Laboratory tests (in Polish language), (Alfa, Warsaw, Poland, 1988)

8. BS 1377 : 1990. Part 2 : Methods of test for soils for civil engineering purposes. Part 2. Classification tests, (British Standards Institution, London, 1990)

9. BS 5930:2015 Code of practice for ground investigations, (British Standards Institution, London, 2015)

10. BS 1377 : 1990. Part 3 : Methods of test for soils for civil engineering purposes. Part 3. Chemical and electro-chemical tests, (British Standards Institution, London, 1990)

11. G. Nguyen, Analysis of determination methods of soil erodibility factor K. Progeo2 project report 10/4/2018 (Bielsko-Bieła, 2018)

12. National Soil Survey Handbook. Part 618 Soil Properties and Qualities (430-618-H, 1st Ed., Amend. 25, Nov 2017) https://directives.sc.egov.usda.gov/OpenNonWebContent.aspx? content=41981.wba

13. G. Nguyen, Quantitative evaluation of slope erosion in Lipnik, Nieboczowy and Międzyrzecze. Progeo2 project Report 10/1/2018 (Bielsko-Bieła, 2018) 